\title{
Noise Artifact
}

National Cancer Institute

\section{Source}

National Cancer Institute. Noise Artifact. NCI Thesaurus. Code C87013.

An artifact that appears as a point to point signal fluctuation in a uniform material. 